\title{
Clinicohematological Profile of Febrile Neutropenia in Childhood Acute Leukemia and Utility of Serum Procalcitonin Levels in Neutropenic Patients
}

\author{
Rajan Kapoor, Ashish K. Simalti', Shuvendu Roy ${ }^{1}$, Pulkit Agarwal ${ }^{1}$ \\ Departments of Hematology and 'Paediatrics, Army Hospital (R and R), New Delhi, India
}

\section{Abstract}

Introduction: This study was planned to explore the clinical and hematological profile of febrile neutropenia (FN) in Indian children with focus on correlation of degree of neutropenia with fever and procalcitonin (PCT) level and the utility of serum PCT levels in cases of FN. Materials and Methods: Children below 12 years, receiving chemotherapy for hematological malignancy having oral temperature more than $100^{\circ} \mathrm{F}$ and absolute neutrophil count (ANC) below $500 / \mathrm{mm}^{3}$ were included. The aim of this study was to observe the clinicohematological profile of FN and utility of serum PCT levels in neutropenic patients. PCT was done by two-step two-site electrochemiluminescence immunoassay. Serum PCT values were reported as nanogram $/ \mathrm{ml}$. Results: Four categories were made based on serum PCT levels which had negative correlation with ANC but no correlation with microbiologically detected infections. Discussion: PCT is generally used to support the diagnosis of bacterial infection or sepsis in the emergency department or to monitor the treatment of sepsis with regard to reviewing antimicrobial treatment. The use of PCT has been well established as a marker for infection in adults and in nonneutropenic children, but similar data are lacking in pediatric population, more so in children with FN in Indian contexts. This study aims to fulfill this lacuna. Conclusion: The higher levels of PCT had a high negative correlation with ANC but low correlation with microbiologically detected infections.

Keywords: Fever, neutropenia, procalcitonin

\section{INTRODUCTION}

Febrile neutropenia (FN) is a fever associated with abnormally low neutrophil count signifying an immune-compromised state secondary to malignancy or its treatment. It is a common and often critical condition that adversely impacts the prognosis of patients. $\mathrm{FN}$ is defined as the single oral temperature above $38^{\circ} \mathrm{C}\left(101^{\circ} \mathrm{F}\right)$ over $1 \mathrm{~h}$ with $<500$ neutrophils $/ \mathrm{mm}^{3}$ or $<1000$ neutrophils $/ \mathrm{mm}^{3}$ with a predicted decline to $500 / \mathrm{mm}^{3}$ over the next $48 \mathrm{~h} \cdot{ }^{[1]}$ The present study was planned to explore the clinical and hematological profile of FN in Indian children with a focus on correlation of degree of neutropenia with fever and procalcitonin (PCT) level and the utility of serum PCT levels in cases of FN. PCT determination is being considered to have significant value in identifying inflammation secondary to bacterial infection. ${ }^{[2]}$ Recently conducted PRORATA trial also advocated PCT-guided strategy to treat possible bacterial infection in nonsurgical patients ${ }^{[3]}$ In view of current interest in determining PCT levels and paucity of Indian studies

\begin{tabular}{|l|l|}
\hline \multicolumn{3}{|c|}{ Access this article online } \\
\hline Quick Response Code: & Website: \\
\hline & www.ijccm.org \\
\hline & \\
\hline
\end{tabular}

correlating PCT levels with FN in childhood acute leukemia, the current study was undertaken.

\section{Materials and Methods}

It was a prospective observational study done for 18 months, from October 2015 to March 2017 at a multispecialty tertiary care center. Based on our patient load, duration of the proposed study, and available resources, a sample size of $50(n=50)$ was decided and 50 febrile episodes associated with neutropenia in children having hematological malignancy were studied. Children below 12 years, receiving chemotherapy for hematological malignancy having oral temperature more

Address for correspondence: Dr. Ashish K. Simalti, Army Hospital (R and R), Delhi Cantt, New Delhi - 110 010, India. E-mail: ashishsimalti@rediffmail.com

This is an open access journal, and articles are distributed under the terms of the Creative Commons Attribution-NonCommercial-ShareAlike 4.0 License, which allows others to remix, tweak, and build upon the work non-commercially, as long as appropriate credit is given and the new creations are licensed under the identical terms.

For reprints contact: reprints@medknow.com

How to cite this article: Kapoor R, Simalti AK, Roy S, Agarwal P. Clinicohematological profile of febrile neutropenia in childhood acute leukemia and utility of serum procalcitonin levels in neutropenic patients. Indian J Crit Care Med 2018;22:336-9. 
than $100^{\circ} \mathrm{F}$, and absolute neutrophil count (ANC) below 500 /cumm were included in this study [Figure 1]. Parents were informed about the study and written consent was obtained for each case. Detailed history and clinical examination were carried out and following investigations were also carried out: hemoglobin, total leukocyte count, differential leukocyte count, ANC, serum PCT, blood culture/sensitivity, urine microscopic examination/routine, examination (ME/RE), urine culture/sensitivity, and chest X-ray posteroanterior view. Biochemical profile, ultrasonography abdomen, and computed tomography (CT) chest were done if indicated. In our center, PCT is done by two-step two-site electrochemiluminescence immunoassay. Serum PCT values were reported as nanogram $/ \mathrm{ml}$. Based on these values, four groups were made [Table 1 and Figure 2]. Group 1 was below 0.5 , Group 2 between 0.5 and 02, Group 3 between 2 and 10 , and Group 4 above $10 \mathrm{ng} / \mathrm{ml}$. The treatments offered to these children in due course of hospitalization included antimicrobial therapy, granulocyte colony-stimulating factor (G-CSF), besides individualized treatment as decided by treating physician.

\section{RESULTS}

It was a prospective observational study with 50 children taken as one group initially and clinical and hematological characteristics as mentioned above were studied. On analyzing, they were subdivided into various categories depending on the parameter being studied, such as associated symptoms and levels of PCT. Chi-square test was used to find out utility of PCT. Correlation was calculated by Spearman's coefficient correlation with value $<0.3$ taken as low and $>0.5$ as high correlation. Out of 50 children satisfying inclusion criteria, $92 \%$ children had acute lymphoblastic leukemia (ALL) (B-cell ALL, Pre-B-cell ALL, and T-cell ALL) as the primary diagnosis. Only one child had AML and three children had an ALL relapse. In this study, we found that the incidence of FN was higher in younger children, highest incidence being in children between 2 and 4 years of age (46\%). The overall incidence among children $<6$ years of age was found to be

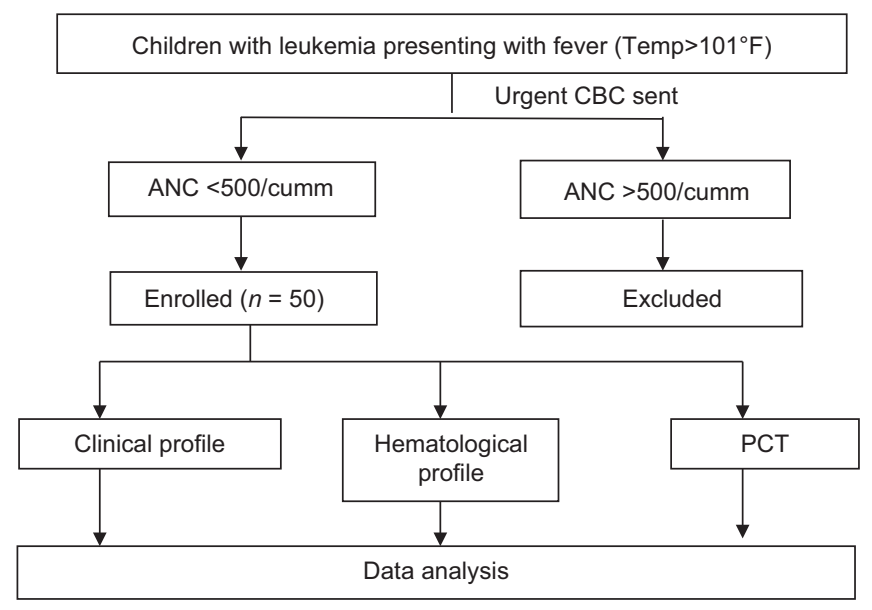

Figure 1: Study flow chart
$82 \%$. Our study also showed a slightly higher incidence of FN in boys (62\%), as compared to girls (38\%). In this study, we found that $60 \%$ of children, who were admitted with FN, had total fever duration of $<72 \mathrm{~h}$. The peak temperature $\left(\mathrm{T}_{\max }\right)$ during these $\mathrm{FN}$ episodes was found to be $<103^{\circ} \mathrm{F}$ most of the times ( $82 \%)$. Analysis of symptoms revealed that $32 \%$ children had respiratory symptoms (cough, running nose, sore throat, breathlessness, and occasionally pleuritic chest pain) along with fever. About $8 \%$ children had symptoms involving the gastrointestinal tract in the form of nausea, vomiting, diarrhea, anorexia, and pain abdomen. However, most children had vague symptoms such as lethargy, irritability, polyarthralgia, and bodyache. In $26 \%$ children, fever was the only presenting symptom. On examination, $24 \%$ children were found to have a respiratory tract involvement in the form of pharyngitis, upper respiratory tract infection, or pneumonia. In $14 \%$ children, a noninfectious inflammatory pathology was found in the form of mucositis (mostly induced by drugs such as methotrexate) or thrombophlebitis due to intravenous cannulae. Soft-tissue infection such as an abscess or lymphadenitis was seen in $4 \%$ children. However, in $58 \%$ children, no obvious focus of infection was found.

Among investigations in our study, $4 \%$ children had profound neutropenia (ANC $<100$ ) while $58 \%$ of children had ANC more than 300. It was also noted that the children with profound neutropenia had a prolonged period of FN and had a fatal outcome. Only $10 \%$ of the children admitted with FN had

\begin{tabular}{|c|c|c|c|c|}
\hline & \multicolumn{4}{|c|}{ Results } \\
\hline & CSI & MDI & NAD & Row totals \\
\hline Group 1 & $3(4.59)(0.55)$ & $1(3.53)(1.81)$ & $14(9.88)(1.72)$ & 18 \\
\hline Group 2 & $2(2.55)(0.12)$ & $2(1.96)(0.00)$ & $6(5.49)(0.05)$ & 10 \\
\hline Group 3 & $5(3.82)(0.36)$ & $3(2.94)(0.00)$ & $7(8.24)(0.19)$ & 15 \\
\hline Group 4 & $3(2.04)(0.45)$ & $4(1.57)(3.77)$ & $1(4.39)(2.62)$ & 8 \\
\hline $\begin{array}{l}\text { Column } \\
\text { totals }\end{array}$ & 13 & 10 & 28 & $\begin{array}{l}51 \text { (grand } \\
\text { total) }\end{array}$ \\
\hline
\end{tabular}

Groups based on procalcitonin values (nanogram $/ \mathrm{ml}$ ), Group 1: $<0.5$, Group 2: 0.5-2, Group 3: 2-10, Group 4: >10. CSI: Clinically significant infection; MDI: Microbiologically defined infection; NAD: No abnormality detected

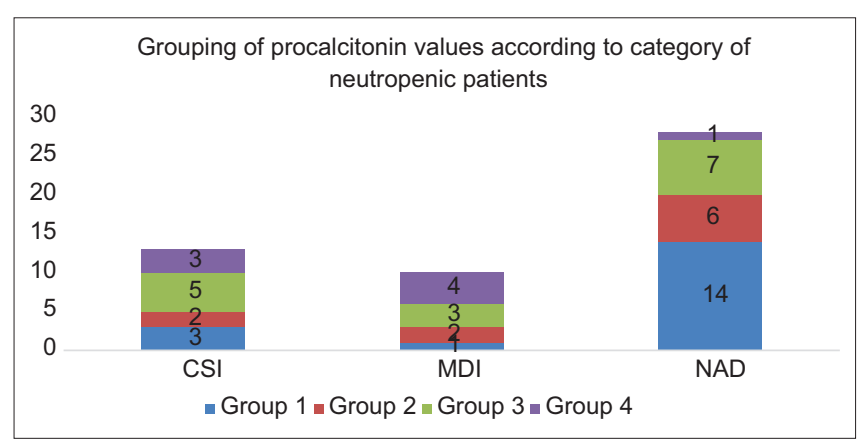

Figure 2: Graphical representation of the level of procalcitonin with type of infection 
associated severe anemia $(<7.0 \mathrm{~g} / \mathrm{dl})$. Correlating PCT levels and categories based on infection by Pearson Chi-square test using statistical software $\mathrm{R}$ version, $P=0.070645$, suggesting that there was no correlation between PCT values and microbiologically documented infection in patients of FN.

Positive blood culture was seen in $6 \%$ cases and a positive urine culture was found in $16 \%$ with $4 \%$ growing the same organism in both urine as well as blood. One child had a positive serum galactomannan report. Any child with any prolonged fever ( $>72 \mathrm{~h}$ ), pneumonia (X-ray/CT scan proven), or any identified focus of infection like abscesses were considered to have clinically significant infection (CSI). A child with FN having positive culture from sterile body fluids (blood, urine, and CSF) was considered to have microbiologically documented infections.

Treatment included G-CSF therapy and antibiotics. G-CSF was stopped, once ANC showed a rising trend. The mean duration of G-CSF was slightly more than the duration of fever in most cases. G-CSF was required for $<4$ days in $70 \%$ children in our study. Moreover, children who required prolonged G-CSF therapy had poor response to G-CSF and poorer prognosis. All patients with FN were started on empirical antibiotic therapy on admission. The antibiotics were continued till 2 days after patient became afebrile and recovery of neutrophil counts. The antibiotic duration in our study was found to be $<7$ days in $76 \%$ cases, while the remaining children required prolonged antibiotics.

\section{Discussion}

FN is a very common and dreaded complication following chemotherapy in hemato-oncological practice ${ }^{[4]}$ Patients with ANC lower than $500 / \mathrm{mm}^{3}$, especially if the number of these white cells is falling rapidly, are considered to be at increased risk of infection and mortality. ${ }^{[5]}$ More than two-thirds of febrile episodes in neutropenic patients are likely to be caused by infection with fever frequently being the only sign of infection. ${ }^{[6]}$ Bacteremia occurs in $10 \%-25 \%$ of all patients, with most episodes occurring in the setting of prolonged or profound neutropenia $\left(\mathrm{ANC}<100\right.$ neutrophils $\left./ \mathrm{mm}^{3}\right)$. $^{[7-9]}$

As the progression of infection in neutropenic patients can be very rapid, such patients with early bacterial infections cannot be reliably distinguished from noninfected patients initially. In 1966, Bodey et al. directed the attention of clinical experts for the first time to the close connection between the severity of infection and the degree and duration of neutropenia among those patients who were receiving chemotherapy for acute leukemia. ${ }^{[7]}$ Empirical antibiotic therapy, therefore, should be administered promptly to all neutropenic patients at the onset of fever.

Systemic bacterial infection is a pro-inflammatory stimulation that induces production of $\mathrm{PCT}$. PCT is produced by numerous cell types and affects the immune response by modulating the induction of pro-inflammatory cytokines. ${ }^{[10,11]}$ PCT is generally used to support the diagnosis of bacterial infection or sepsis in the emergency department or to monitor the treatment of sepsis with regard to reviewing antimicrobial treatment (generally in a critical care environment). The use of PCT has been well established as a marker for infection in adults and nonneutropenic children, but similar data are lacking in pediatric population, more so in children with $\mathrm{FN}$ in Indian contexts. ${ }^{[12,13]}$ In addition, there is scarce data regarding correlation of the degree of fever with the degree of neutropenia (estimated by ANC). The duration of required G-CSF in children with FN has not been analyzed in any previous study.

The duration of antibiotics is longer in cases of microbiologically documented or CSIs as per the existing guidelines. ${ }^{[14]}$ This correlates with the $78 \%$ children, in which no focus of infection was found in our study. These findings may suggest that all children with FN may not have a significant infective pathology. These cases of FN, especially those with fever $>72 \mathrm{~h}$ without an identifiable focus, may have been caused by various noninfective inflammatory conditions.

The correlation between ANC and temperature was found to be -0.219 and ANC cannot be used to predict the maximum temperature and vice versa [Table 2]. In our study, there was no correlation between PCT values and microbiologically documented infection in patients of FN since $P$ value in Pearson Chi-squared test came to 0.070645 .

There are few limitations to this study. First, this study has its findings based on a single sample drawn during a period of FN. There was no serial monitoring of ANC or PCT. The same would have offered better result and inferences. Moreover, the duration of neutropenia was not studied which is an important prognostic marker for predicting the outcome in such cases. ${ }^{[15]}$ Second, the presence or absence of central IV lines, bladder catheters, etc., were not considered in the methodology which are important causes of fever frequently in such patients. Although there are significant differences in the incidence of FN based on primary diagnosis and gender in our study, total

\begin{tabular}{|c|c|c|c|}
\hline Correlations & ANC & Temperature ( $\left.{ }^{\circ} \mathrm{F}\right)$ & РCT \\
\hline \multicolumn{4}{|l|}{ ANC } \\
\hline Pearson correlation & 1 & -0.219 & -0.501 \\
\hline Significant (two-tailed) & & 0.127 & 0 \\
\hline$n$ & 50 & 50 & 50 \\
\hline \multicolumn{4}{|l|}{ Temperature $\left({ }^{\circ} \mathrm{F}\right)$} \\
\hline Pearson correlation & -0.219 & 1 & 0.477 \\
\hline Significant (two-tailed) & 0.127 & & 0 \\
\hline$n$ & 50 & 50 & 50 \\
\hline \multicolumn{4}{|l|}{ PCT } \\
\hline Pearson correlation & $-0.501 * *$ & $0.477 * *$ & 1 \\
\hline Significant (two-tailed) & 0 & 0 & \\
\hline$n$ & 50 & 50 & 50 \\
\hline
\end{tabular}

ANC: Absolute neutrophil count; PCT: Procalcitonin 
number enrolled is far too less for these findings to determine if this will be applicable to general population. Overall, the sample size taken was inadequate to determine whether the findings of the study were statistically significant.

\section{Conclusion}

The initial presentation on FN was quite variable, but signs and symptoms suggestive of the respiratory tract involvement are most common. However, in most cases, no focus of infection could be found. The higher levels of PCT and ANC had low correlation with temperature. As per the findings of our study, PCT should not be used as surrogate marker for bacterial infection in patients with FN because of poor correlation with microbiologically detected infection. But owing to relatively small sample size of our study, further studies with larger populations are required to validate these findings.

\section{Financial support and sponsorship}

Nil.

\section{Conflicts of interest}

There are no conflicts of interest.

\section{References}

1. Özdemir N, Tüysüz G, Çelik N, Yantri L, Erginöz E, Apak H, et al. Febrile neutropenia in children with acute lymphoblastic leukemia: Single center experience. Turk Pediatri Ars 2016;51:79-86.

2. Jin M, Khan AI. Procalcitonin: Uses in the clinical laboratory for the diagnosis of sepsis. Lab Med 2010;41:173-7.

3. Bouadma L, Luyt CE, Tubach F, Cracco C, Alvarez A, Schwebel C, et al. Use of procalcitonin to reduce patients' exposure to antibiotics in Intensive Care Units (PRORATA trial): A multicentre randomised controlled trial. Lancet 2010;375:463-74.
4. Sharma A, Lokeshwar N. Febrile neutropenia in haematological malignancies. J Postgrad Med 2005;51 Suppl 1:S42-8.

5. Santolaya ME, Alvarez AM, Becker A, Cofré J, Enríquez N, O'Ryan M, et al. Prospective, multicenter evaluation of risk factors associated with invasive bacterial infection in children with cancer, neutropenia, and fever. J Clin Oncol 2001;19:3415-21.

6. Huges WT, Armstrong D, Bodey GP, Feld R, Mandell GL, Meyers JD, et al. Guidelines for the use of antimicrobial agents in neutropenic patients with unexplained fever: A statement by the Infectious Diseases Society of America. J Infect Dis 1990;16:381.

7. Bodey GP, Buckley M, Sathe YS, Freireich EJ. Quantitative relationships between circulating leukocytes and infection in patients with acute leukemia. Ann Intern Med 1966;64:328-40.

8. Rosenberg PS, Alter BP, Bolyard AA, Bonilla MA, Boxer LA, Cham B, et al. The incidence of leukemia and mortality from sepsis in patients with severe congenital neutropenia receiving long-term G-CSF therapy. Blood 2006;107:4628-35.

9. Ramphal R. Changes in the etiology of bacteremia in febrile neutropenic patients and the susceptibilities of the currently isolated pathogens. Clin Infect Dis 2004;39 Suppl 1:S25-31.

10. Kitanovski L, Jazbec J, Hojker S, Gubina M, Derganc M. Diagnostic accuracy of procalcitonin and interleukin-6 values for predicting bacteremia and clinical sepsis in febrile neutropenic children with cancer. Eur J Clin Microbiol Infect Dis 2006;25:413-5.

11. Fleischhack G, Kambeck I, Cipic D, Hasan C, Bode U. Procalcitonin in paediatric cancer patients: Its diagnostic relevance is superior to that of C-reactive protein, interleukin 6, interleukin 8, soluble interleukin 2 receptor and soluble tumour necrosis factor receptor II. Br J Haematol 2000;111:1093-102.

12. Schneider HG, Lam QT. Procalcitonin for the clinical laboratory: A review. Pathology 2007;39:383-90.

13. Tang BM, Eslick GD, Craig JC, McLean AS. Accuracy of procalcitonin for sepsis diagnosis in critically ill patients: Systematic review and meta-analysis. Lancet Infect Dis 2007;7:210-7.

14. Downes KJ, Zaoutis TE, Shah SS. Guidelines for management of children with fever and neutropenia. J Pediatric Infect Dis Soc 2013;2:281-5.

15. Hughes WT, Armstrong D, Bodey GP, Bow EJ, Brown AE, Calandra T, et al. 2002 guidelines for the use of antimicrobial agents in neutropenic patients with cancer. Clin Infect Dis 2002;34:730-51. 